\title{
Number of children and the prevalence of later-life major depression and insomnia in women and men: findings from a cross-sectional study of 0.5 million Chinese adults.
}

\author{
Hanyu Wang \\ Peking University Health Science Centre \\ Minne Chen \\ Marie Stopes International \\ Tong Xin \\ Peking University Health Science Centre \\ Kun Tang ( $\nabla$ tangkun@post.harvard.edu ) \\ Tsinghua University https://orcid.org/0000-0002-5444-186X
}

\section{Research article}

Keywords: Major Depression; Insomnia; Parity; Sex Differences; China

Posted Date: November 13th, 2019

DOI: https://doi.org/10.21203/rs.2.17262/v1

License: (c) (i) This work is licensed under a Creative Commons Attribution 4.0 International License. Read Full License

Version of Record: A version of this preprint was published at BMC Psychiatry on May 29th, 2020. See the published version at https://doi.org/10.1186/s12888-020-02681-2. 


\section{Abstract}

Pregnancy and parenthood have been associated with physical and mental health. Previous literature concerning the impacts of parity on mental health was inconsistent and lack epidemiolocal evidence. China, with growing mental health problems and changing fertility patterns, faces unique challenges. This study aims to examine the relationship between parity and the prevalence of major depression and insomnia among men and women in the Chinese population. Methods Baseline data from a Chinese population-based study of 512,891 adults (59.01\% women) from 10 areas, aged 30-79 were analyzed. Number of children were based on self-report by the participants. Major depression (MD) was assessed using the Composite International Diagnostic Inventory. Insomnia symptoms were accessed by questionnaire comparable to that used in Diagnostic and Statistical Manual of Mental Disorders. Logistic regression was used to assess the relationship between MD/Insomnia and number of children, after stratifications and adjustments. Results For women, each additional child was associated with a $9 \%$ decreased odds of MD (OR: 0.91, 95\% Cl: 0.88-0.96), with the associations significant for those who lived in urban areas (OR: $0.76,95 \% \mathrm{Cl}: 0.70-$ 0.83), or had a lower education (OR: $0.90,95 \% \mathrm{Cl}$ : 0.85-0.94), or had lower household income (OR: $0.89,95 \% \mathrm{Cl}$ : $0.85-$ 0.94), or had ever used alcohol (OR: $0.89,95 \% \mathrm{Cl}$ : 0.84-0.93). The association between per additional children and MD was not significant in men (OR: 1.02, 95\% Cl: 0.97-1.07) but a decreased odds of MD with per additional child was found in men who lived in urban areas (OR: $0.81,95 \% \mathrm{Cl}$ : 0.71-0.96). For women, each additional child was associated with a $4 \%$ decreased odds of insomnia (OR: 0.96, 95\% Cl: 0.95-0.96). Each additional child was also associated with a $2 \%$ decreased odds of insomnia in men (OR: $0.98,95 \% \mathrm{Cl}: 0.97-1.00)$. Conclusions MD and insomnia was associated with number of children, particularly in women and the association was mediated by socioeconomic and lifestyle factors. Future mental health public health programs should address parity and sex differences when designing interventions.

\section{Introduction}

Pregnancy and parenthood have been associated with physical and psychological health through physiological and socioeconomic mechanisms in previous literature [1-14]. Previous epidemiological research also showed that parity and parenthood were related to major diseases, including cardiovascular [1, 2], endocrine disease [3, 4], and cancer [5].

There was also a growing body of literature focusing on the psychological impacts of pregnancy, parity, and parenthood [6-14]. Physiological research found that estrogen level was affected by women's reproductive history and subsequently influenced mental health outcomes [15-17]. Studies also found that early age at first birth was associated with adverse later-life mental health outcomes $[6,13]$. Sociological studies also observed that number of children was related to mental health outcomes $[10,11,13,14]$. A study conducted in 24 European countries observed that childless was associated with adverse mental health outcomes, with social pressure and gender mediating the association [10]. There was a positive relationship between number of children and later-life depression observed in Eastern Europe but not Western Europe and the association was affected by marital status and economic development of the countries [14]. A study in England also observed that more children were associated with worsened mental health among older population and the association was mediated by wealth and lifestyle factors [13]. A recent study conducted in affluent areas in China found that more pregnancies were associated with higher prevalence of depressive symptoms later in life [11]. Djundeva el al found that the association between children and later-life depression in Chinese elders was complicated by urbanization, gender preference, and modernization [12]. Psychological studies concluded that the association and pathways were highly complicated by life course, genderrelated, socioeconomic, and cultural factors [7-9]. 
Previous literature, however, focused mostly on the psychological perspective of childrearing or physiological mechanisms of pregnancy rather than reproductive history and they are mostly without sound epidemiological evidence [6-10, 12, 15-17]; or explored the psychological, social perspective, including social capita or payback of having children with very limited medical interpretations [7, 13, 14]. Most studies were conducted in western population $[6-10,13,14]$ and the studies conducted in China had a small and limited sample, e.g. the sample is homogenous in terms of socio-demographic variants $[11,12]$.

The relationship between parity and mental status is particularly relevant to the Chinese population because of the rising mental health problems with poor mental healthcare, growing economic disparity, urban-rural migration, stressed working environment [18-20], the changing patterns of fertility behaviors[21], and the recently launched twochild policy[22]. Thus, population-based large scale study exploring the association between number of children and later-life mental health outcomes in China is needed to close the gap in epidemiological literature and also provide evidence for policymakers and those who intended to improve mental health to make decisions and implement interventions.

This study aims to examine the relationship between parity and the prevalence of major depression and insomnia of half a million individuals from 10 diverse regions in China, with the consideration of socioeconomic and lifestyle factors. This study also examined the associations separately among women and men in this study population in order to differentiate biological and socioeconomic factors.

\section{Methods}

\subsection{Sampling}

The data were obtained from the baseline survey of a large cohort study conducted between 2004 to 2008 in 10 geographically defined areas. Details of the study design and sample characteristics could be found elsewhere [23]. The regional study sites were selected carefully to retain geographic and social diversity, and to maximize difference in disease rates and risk exposure, so that they could approximate nationally representative samples. Potential participants were approached by community health workers. Over $99 \%$ consented to participate in the baseline assessment. In total, 512,891 adults, including 302,632 (59\%) women aged 30-79 years, approximately $30 \%$ of the total population of the 10 regions sampled, were recruited and completed interviewer-administered electronic questionnaire and clinic visits. A structured interview was conducted by community health workers during the clinical visit, covering socioeconomic factors, mental health related questions, and sleeping patterns. Physical metrics (e.g. height, weight, waist and hip circumference) were also recorded.

\subsection{Exposures}

Number of children was based on the self-report by the participants. The question: "How many children do you have" was asked by the interviewers of the questionnaire and participants reported the current numbers of their children.

\subsection{Outcomes}

In the present study, Chinese version of computerized Composite International Diagnostic Inventory-Short Form (CIDI$\mathrm{SF}$ ) was employed to access major depression (MD). The evaluation was delivered face-to-face by trained community health workers at local clinics [24]. As a diagnostic instrument, the CIDI is based on criteria of the Diagnostic and Statistical Manual of Mental Disorders-IV (DSM-IV) which is proven to be generally equal to clinical psychiatric interviews [24]. The estimates of MD in the population level as accessed by the Chinese version of the CIDI were 
similar to those accessed by the Structured Clinical Interview for DSM $[25,26]$. In the diagnostic tool, the participants with the presence of dysphoria and/or anhedonia accompanied by a clustering of somatic, cognitive, and behavioral disturbances, including appetite or weight change, feelings of guilt or worthlessness, sleeping problems, fatigue, psychomotor changes, concentration problems, and thoughts of suicide that lasted two weeks or more were diagnosed as having MD $[25,26]$.

The present study employed a tool similar to that used in Diagnostic and Statistical Manual of Mental Disorders (DSM-IV-TR) or Research Diagnostic Criteria (RDC) or International Classification of Sleep Disorders (ICSD) to access insomnia. During the interview, there were three questions to access insomnia: (1) taking >30 min to fall asleep after going to bed or waking up in the middle of the night, (2) waking up early and not being able to go back to sleep and (3) needing to take medicine (including herbal or sleeping pills) at least once a week to help sleep. The interviewers asked the participants if they had any of the above three symptoms in at least three days or more in a week during the last month. If the participants answered 'Yes' to any of the above symptoms, then they were considered as having insomnia [27].

\subsection{Other co-variates}

Demographic and socio-economic characteristics collected in the baseline survey, specifically age at study date, sex, household size, highest level of education, and occupation, were included as co-variates in the analysis. Highest level of education was categorized into primary school/below and high school/above. Occupation was categorized into agriculture and related workers, factory workers, clerks and unemployed. Participants' health behaviors, including smoking status and alcohol use, were classified as "never," "ever use". BMI was calculated as weight in kilograms divided by height in meters squared [23]. BMI $\left(\mathrm{kg} / \mathrm{m}^{2}\right)$ was categorized as $<20,20-25$, and $>25 \mathrm{~kg} / \mathrm{m}^{2}$, which was based on standard classification specific for the Chinese population [28].

Self-rated health was accessed by asking the participants: "How is your current general health status: excellent, good, fair, or poor?" in baseline interview and classified into four categories accordingly.

\subsection{Data analysis}

Descriptive analyses were used to illustrate the basic demographic, socioeconomic and lifestyle factors for those people with no child, one child, two children, and more than two children. Means (SD) and percentages were presented as descriptive results. Logistic regression models were fitted to explore the association between number of children and MD and insomnia prevalence. Odds Ratios (ORs) and 95\% Cls were calculated to explore the association between MD and insomnia by the number of children, stratified by sexes. One child group was chosen as the reference group for the analysis. Two types of logistic regression models were fitted: 1) crude 2) fully adjusted (adjusted for rural/urban, marital status, age at study date, level of attained education, household income, smoking status, alcohol use, self-rated health, occupation, BMI). To understand how rural/urban, age, education, household income, smoking, alcohol use, and BMI potentially modify the associations between number of children and MD/insomnia, adjusted sexspecific ORs and 95\% Cls for MD and insomnia per additional child stratified by the variables described above were calculated, after adjusting for study region, marital status, age at study date, highest education, household income, smoking status, alcohol use, self-rated health, occupation, BMI, where appropriate. All the data analysis was conducted by SAS version 9.4 (SAS Institute, Cary, NC, USA).

\section{Results}


Detailed baseline characteristics of participants by number of children were presented in Table 1. Of all 512,891 participants included in the analysis, there were 10,300 with no child (2.01\%), 183,628 with one child (35.80\%), 166,394 with two children (32.44\%) and 152,539 with more than two children (29.74\%). The mean age of the study population for those with no child, one child, two children, and more than two children was 49.55 (SD=12.04), 45.26 $(S D=7.37), 50.64(S D=9.34)$, and $60.18(S D=9.47)$ respectively. Compared to participants with one child, those with no or more than one child were generally older, less educated, had a lower household income, and generally had a lower self-rated health. Those with one child were also less likely to have agriculture and related occupations (24.17\%) compared with those with no child $(39.96 \%)$ or more than one child $(52.46 \%$ for those with 2 children and $51.26 \%$ for those with more than three children). Childless participants were much less likely to be married (51.08\%) compared to those who had children. The prevalence of ever smoke was considerably higher in those with no child (51.86\%) compared to those with children. Participants with no child $(61.70 \%)$ or one child $(62.73 \%)$ had a higher percentage of using alcohol, compared to those with two $(51.42 \%)$ or more $(46.26 \%)$ children. Detailed percentages and figures could be referred to Table 1 .

Table 2 presents the sex-specific association between number of children and MD/insomnia. The overall MD prevalence for females and males was $0.78 \%$ and $0.46 \%$, respectively. The overall insomnia prevalence for females and males was $18.86 \%$ and $13.69 \%$, respectively. In the fully adjusted model, the odds of MD is 1.27 times greater for those with no child (OR: 1.27, 95\% Cl: 1.00-1.62), compared to those with one child, and the association was only observed in women after stratified by sexes (OR:1.38, 95\% Cl: 1.03-1.87). Having two (OR: 0.95, 95\% Cl: 0.93-0.97) or more (OR: $0.91,95 \% \mathrm{Cl}: 0.89-0.94)$ children were associated with lower odds of insomnia in the total population compared to those with one children and the association only existed in women (OR: $0.94,95 \% \mathrm{Cl}: 0.91-0.96$ for women with two children and OR: $0.88,95 \% \mathrm{Cl}$ : $0.85-0.90$ for women with three children) after stratification of sexes. The detailed ORs and 95\% Cls could be referred to in Table 2.

Figure 1 presented the adjusted odds ratios for major depression per additional child by baseline characteristics in women and men. For women, each additional child was associated with a 9\% decreased odds of MD (OR: 0.91, 95\%Cl: 0.88-0.96), with the associations significant for those who lived in urban areas (OR: $0.76,95 \% \mathrm{Cl}: 0.70-0.83$ ), or had a lower education (OR: 0.90, 95\% Cl: 0.85-0.94), or had lower household income (OR: 0.89, 95\% Cl: 0.85-0.94), or had ever used alcohol (OR: $0.89,95 \% \mathrm{Cl}$ : 0.84-0.93). The association between per additional children and MD was not significant in men (OR: $1.02,95 \% \mathrm{Cl}: 0.97-1.07)$ but a decreased odds of MD with per additional child was found in men lived in urban areas (OR: 0.81, 95\% Cl: 0.71-0.96).

Figure 2 presented the adjusted odds ratios for insomnia per additional child by baseline characteristics in women and men. For women, each additional child was associated with a 4\% decreased odds of insomnia (OR: 0.96, 95\% Cl: 0.950.96), with the associations significant for those who lived in rural areas (OR: 0.94, 95\% Cl: 0..93-0.95), or aged less than 60 (OR: $0.96,95 \% \mathrm{Cl}$ : 0.94-0.97), or had a lower household income (OR: 0.95, 95\%Cl: 0.94-0.96), or never smoked (OR: $0.95,95 \% \mathrm{Cl}: 0.94-0.96)$. Each additional child was also associated with a $2 \%$ decreased odds of insomnia in men (OR: $0.98,95 \% \mathrm{Cl}: 0.97-1.00)$, with the household income appearing to significantly modify the association (OR: 0.97 , 95\% Cl: $0.95-0.98$ for those with household income<10,000 Yuan and OR: 1.04, 95\%Cl: 1.01-1.06 for those with household income $\geq 10,000$ Yuan).

\section{Discussion}

We found that number of children were associated with a decreased prevalence of depression in women but not in men. Number of children were also observed to be associated with decreased prevalence of insomnia in women and, less significantly, in men. Region appeared to have strong modifying effects of the associations while other

Page 5/13 
socioeconomic status, including age, educational attainments, household income, and lifestyle factors (alcohol use and smoking behavior) also influenced the association.

In the present study, number of children were observed to be associated with better mental outcomes in women. Research exploring the association between number of children and later-life depression was scarce and the results were inconsistent with negative associations [29, 30], positive associations [11, 13, 14, 31], and no association [32] observed and the associations were complicated by hormones, socioeconomic, and lifestyle factors [11, 13, 14, 29-32]. In the present study, the trend of the association between mental outcomes and number of children was different among men and women. Thus, the physiological and social pathways are both possible. A recent study conducted in China found that having more birth was associated with increased risk of later-life depression for women and they hypothesized hormone level as the main mediator of the association [11]. Studies found that though endogenous estrogen level was high during pregnancy, women with more parity had lower circulating estrogen over a lifetime than those with fewer parity or nulliparity $[15,16]$ and estrogen generally had antidepressant effects [17]. In the Chinese culture in particular, however, more children and larger family were considered as blessing, which became especially true when one is older [33]. More children generally represented stronger social support, which is a strong contributor to better mental health outcomes [34]. It was possible that though the overall estrogen level increased the depression risk in later life, the positive cultural and social factors accompanied by more children overweighed the negative effects in the study population.

The associations between number of children and mental health outcomes were stronger in women than men. Firstly, the overall prevalence of major depression and insomnia was about 50 percent higher for women than men, which was consistent was previous literature [35]. Higher prevalence in the women sub-group made it more likely to demonstrate statistically significant results, which might partly contribute to the stronger association. While more birth was associated with low estrogen level that increased depression risk [15-17], it was also possible that the social and cultural benefits of more children were much stronger for females than males. In traditional Chinese value, high fertility level was seen as blessing for females [36]. At the same time, females in China are more likely to be in lower social strata than males $[36,37]$, which means that they need more support from children in later life.

The associations between parity and major depression and insomnia were observed to be influenced by region, among other socio-economic and lifestyle factors. The protective effect of more children on major depression was significant in urban areas but disappeared in rural areas for both men and women. With the unprecedented economic growth, there has been a huge rural-urban migration of working-age adults in China [38]. This left middle-age and older people behind in rural areas, always alone, sometimes with grandchildren and living in a relatively deprived community $[38,39]$. Previous studies have demonstrated that left-behind people in rural areas face a much higher risk of depression than their counterpart in urban areas $[39,40]$. Moreover, previous research showed that middle-aged and older people in rural areas in China who lived in skipped generation households were observed to be less happy [39], which means that the pressure of rising grandchildren might also increase the risk of depression for people in rural areas. Thus, additional child in rural areas might not bring actual benefits for the parents because the children migrated to urban areas and they also have to face the burden of raising the grandchildren.

This paper exhibits several strengths. First, although the data is cross-sectional, there is an inherent temporal effect between the parity and the time of the survey. Second, it is one the first papers that examines the association between number of children and prevalence of depression/insomnia in women and men simultaneously in China. In addition, the data we used is the largest cross-sectional study in China that incorporates data on depression and the number of children. The sample was representative to infer an association at a national level. We also included a range of socio- 
economic variables, which allow us to explore the mediating effects and underlying pathways. The sex-segregated results generated by the present study might guide further mental public health policies.

The paper also has several limitations. First, the study is a cross-sectional study instead of a longitudinal study. While people's situation may change with the elapse of time, longitudinal data would allow a better understanding of the causal pathways of number of children and subsequent mental health outcomes. Second, the underlying reasons for people to have children or not, or have how many children, were complicated by political, socio-economic, as well as biological factors. There was no way for us to discover these underlying reasons, which might influence the associations observed in the present study. Lastly, depression and insomnia are complex physiological and psychological disorders, though we adjusted a wide range of socioeconomic and lifestyle factors, residual confounding by other factors, including political, social, or psychological determinants, could also influence the associations.

\section{Conclusions}

In the present study, number of children was negatively associated with the prevalence of major depression and insomnia. The associations were particularly significant for women. The associations were mediated by socioeconomic factors in general and region in particular. Public health interventions that aim at improving the mental health of middle-aged and older people should consider their number of children and related socioeconomic and lifestyle factors. The Chinese government has announced in 2015 that China's one-child policy has been lifted and is to be replaced by a universal two-child policy, which might alter the fertility pattern and subsequently influence people's mental health. Further studies are needed to follow-up and identify the potential effects of the new policy on the well-being of the Chinese people.

\section{List Of Abbreviations}

MD: Major Depression

CIDI-SF: Composite International Diagnostic Inventory-Short Form

DSM-IV: Diagnostic and Statistical Manual of Mental Disorders-IV

BMI: Body Mass Index

ORs: Odds Ratios

SD: Standard deviation

\section{Declarations}

\section{Ethics approval and consent to participate}

The authors assert that all procedures contributing to this work comply with the ethical standards of the relevant national and institutional committees on human experimentation and with the Helsinki Declaration of 1975, as revised in 2008.

This study has been approved by the Institutional Review Boards at Oxford University and the China National Center for Disease Control. 
All the participants included in this study provided written informed consent.

\section{Consent for publication}

Not applicable.

Availability of Data and Materials.

The data that support the findings of this study are available on request from the corresponding author.

\section{Conflicts of interest}

None.

\section{Funding}

This research received no specific grant from any funding agency, commercial or not-for-profit sectors.

\section{Authors' contributions}

H.W. and K.T. contributed to the study concept and design, statistical analysis, results interpretation, and drafting and revision of the manuscript. M.C. and T.X. contributed to the study concept and design, drafting and revision of the manuscript. All authors read and approved the final version of the manuscript.

\section{Acknowledgements}

We are grateful for Clinical Trial Service Unit and Epidemiological Studies Unit (CTSU), Nuffield Department of Population Health, University of Oxford, Oxford, UK, for providing the data.

\section{References}

1. Parikh NI, Cnattingius S, Dickman PW, Mittleman MA, Ludvigsson JF, Ingelsson E: Parity and risk of later-life maternal cardiovascular disease. American heart journal 2010, 159(2):215-221. e216.

2. Peters SA, Yang L, Guo Y, Chen Y, Bian Z, Millwood IY, Wang S, Yang L, Hu Y, Liu J: Parenthood and the risk of cardiovascular diseases among $\mathbf{0 . 5}$ million men and women: findings from the China Kadoorie Biobank. International journal of epidemiology 2017, 46(1):180-189.

3. Peters SA, Yang L, Guo Y, Chen Y, Bian Z, Millwood IY, Bragg F, Zhou X, Ge P, Chen B: Parenthood and the risk of diabetes in men and women: a 7 year prospective study of 0.5 million individuals. Diabetologia 2016, 59(8):16751682.

4. Naver K, Lundbye-Christensen S, Gorst-Rasmussen A, Nilas L, Secher N, Rasmussen S, Ovesen P: Parity and risk of diabetes in a Danish nationwide birth cohort. Diabetic Medicine 2011, 28(1):43-47.

5. Bai Y, Wang X, Yang Y, Tang Y, Wang J, Han P: Parity and bladder cancer risk: a dose-response meta-analysis. BMC cancer 2017, 17(1):31.

6. Mirowsky J, Ross CE: Depression, parenthood, and age at first birth. Social Science \& Medicine 2002, 54(8):12811298.

7. Umberson D, Pudrovska T, Reczek C: Parenthood, childlessness, and well-being: A life course perspective. Journal of Marriage and Family 2010, 72(3):612-629. 
8. Nelson SK, Kushlev K, Lyubomirsky S: The pains and pleasures of parenting: When, why, and how is parenthood associated with more or less well-being? Psychological Bulletin 2014, 140(3):846.

9. Nelson-Coffey SK, Killingsworth M, Layous K, Cole SW, Lyubomirsky S: Parenthood Is Associated With Greater Well-Being for Fathers Than Mothers. Personality and Social Psychology Bulletin 2019:0146167219829174.

10. Huijts T, Kraaykamp G, Subramanian SV: Childlessness and psychological well-being in context: A multilevel study on 24 European countries. European Sociological Review 2011, 29(1):32-47.

11. Li F, He F, Sun Q, Li Q, Zhai Y, Wang X, Zhang T, Lin J: Reproductive history and risk of depressive symptoms in postmenopausal women: A cross-sectional study in eastern China. Journal of affective disorders 2019, 246:174181.

12. Djundeva M, Emery T, Dykstra PA: Parenthood and depression: is childlessness similar to sonlessness among Chinese seniors? Ageing \& Society 2018, 38(10):2097-2121.

13. Grundy E, Read S: Pathways from fertility history to later life health: results from analyses of the English Longitudinal Study of Ageing. Demographic Research 2015, 32(4):107-146.

14. Grundy E, van den Broek T, Keenan K: Number of children, partnership status, and later-life depression in Eastern and Western Europe. The Journals of Gerontology: Series B 2017, 74(2):353-363.

15. Bernstein L, ., Pike MC, Ross RK, Judd HL, Brown JB, Henderson BE: Estrogen and sex hormone-binding globulin levels in nulliparous and parous women. Journal of the National Cancer Institute 1985, 74(4):741-745.

16. Hankinson SE, Colditz GA, Hunter DJ, Manson JE, Willett WC, Stampfer MJ, Longcope C, ., Speizer FE: Reproductive factors and family history of breast cancer in relation to plasma estrogen and prolactin levels in postmenopausal women in the Nurses' Health Study (United States). Cancer Causes \& Control 1995, 6(3):217224.

17. Maria-Angeles A, I? Igo A, Garcia-Segura LM: The neuroprotective actions of oestradiol and oestrogen receptors. Nature Reviews Neuroscience 2015, 16(1):17.

18. Xiang Y-T, Yu X, Sartorius N, Ungvari GS, Chiu HF: Mental health in China: challenges and progress. The Lancet 2012, 380(9855):1715-1716.

19. Gong P, Liang S, Carlton EJ, Jiang Q, Wu J, Wang L, Remais JV: Urbanisation and health in China. The Lancet 2012, 379(9818):843-852.

20. Wong DFK, He X, Leung G, Lau Y, Chang Y: Mental health of migrant workers in China: prevalence and correlates. Social psychiatry and psychiatric epidemiology 2008, 43(6):483-489.

21. Cai Y: China's below-replacement fertility: government policy or socioeconomic development? Population and Development Review 2010, 36(3):419-440.

22. Zeng Y, Hesketh T: The effects of China's universal two-child policy. The Lancet 2016, 388(10054):1930-1938.

23. Chen Z, Chen J, Collins R, Guo Y, Peto R, Wu F, Li L: China Kadoorie Biobank of $\mathbf{0 . 5}$ million people: survey methods, baseline characteristics and long-term follow-up. International journal of epidemiology 2011, 40(6):1652-1666.

24. Kessler RC, Andrews G, Mroczek D, Ustun B, Wittchen HU: The world health organization composite international diagnostic interview short-form (CIDI-SF). International journal of methods in psychiatric research 1998, 7(4):171185.

25. Mezuk B, Chen Y, Yu C, Guo Y, Bian Z, Collins R, Chen J, Pang Z, Wang H, Peto R: Depression, anxiety, and prevalent diabetes in the Chinese population: findings from the China Kadoorie Biobank of 0.5 million people. Journal of psychosomatic research 2013, 75(6):511-517.

26. Chen Y, Bennett D, Clarke R, Guo Y, Yu C, Bian Z, Ma L, Huang Y, Sun Q, Zhang N: Patterns and correlates of major depression in Chinese adults: a cross-sectional study of $\mathbf{0 . 5}$ million men and women. Psychological medicine 
2017, 47(5):958-970.

27. Chen Y, Kartsonaki C, Clarke R, Guo Y, Yu C, Bian Z, Jiang Q, Li S, Chen J, Li L: Characteristics and correlates of sleep duration, daytime napping, snoring and insomnia symptoms among $\mathbf{0 . 5}$ million Chinese men and women. Sleep medicine 2018, 44:67-75.

28. Chen C, Lu FC: The guidelines for prevention and control of overweight and obesity in Chinese adults. Biomedical \& Environmental Sciences Bes 2004, 17 Suppl(Suppl):1.

29. Florence P, Joanne R, Marie-Laure A, Sylvie M, Fran?Oise CC: Lifetime endogenous reproductive factors and severe depressive symptoms in postmenopausal women: findings from the E3N cohort. Menopause-the Journal of the North American Menopause Society 2013, 20(11):1154-1163.

30. Tsai KW, Lin SC, Koo M: Correlates of depressive symptoms in late middle-aged Taiwanese women: findings from the 2009 Taiwan National Health Interview Survey. Bmc Womens Health 2017, 17(1):103.

31. Sa` gsöz N, O`guztürk Ö, Bayram M, Kamacı M: Anxiety and depression before and after the menopause. Archives of Gynecology \& Obstetrics 2001, 264(4):199-202.

32. Joanne R, Isabelle C, Jacqueline S, Karen R, Marie-Laure A: Lifetime hormonal factors may predict late-life depression in women. International Psychogeriatrics 2008, 20(6):1203-1218.

33. Lee GL, Chan CHY, Hui E, Chan CLW: Chinese traditional belief systems, livelihood and fertility. Faith and fertility: Attitudes towards reproductive practices in different religions from ancient to modern times 2009:137-157.

34. Santini ZI, Koyanagi A, Tyrovolas S, Mason C, Haro JM: The association between social relationships and depression: a systematic review. Journal of affective disorders 2015, 175:53-65.

35. Kuehner C: Why is depression more common among women than among men? The Lancet Psychiatry 2017, 4(2):146-158.

36. Zhang C, Li T: Culture, fertility and the socioeconomic status of women. China Economic Review 2017, 45:279288.

37. Asadullah MN, Xiao S, Yeoh E: Subjective well-being in China, 2005-2010: The role of relative income, gender, and location. China Economic Review 2018, 48:83-101.

38. Connelly R, Maurer-Fazio M: Left behind, at-risk, and vulnerable elders in rural China. China Economic Review 2016, 37:140-153.

39. Wen M, Ren Q, Korinek K, Trinh HN: Living in skipped generation households and happiness among middle-aged and older grandparents in China. Social Science Research 2019.

40. Song Q: Facing "double jeopardy"? Depressive symptoms in left-behind elderly in rural China. Journal of aging and health 2017, 29(7):1182-1213.

\section{Tables}

Table 1 Basic characteristics of participants 
Number of children

$\begin{array}{lll}\text { No Child } & \text { Children }=1 \quad \text { Children }=2 & \text { Children } \geq 3\end{array}$

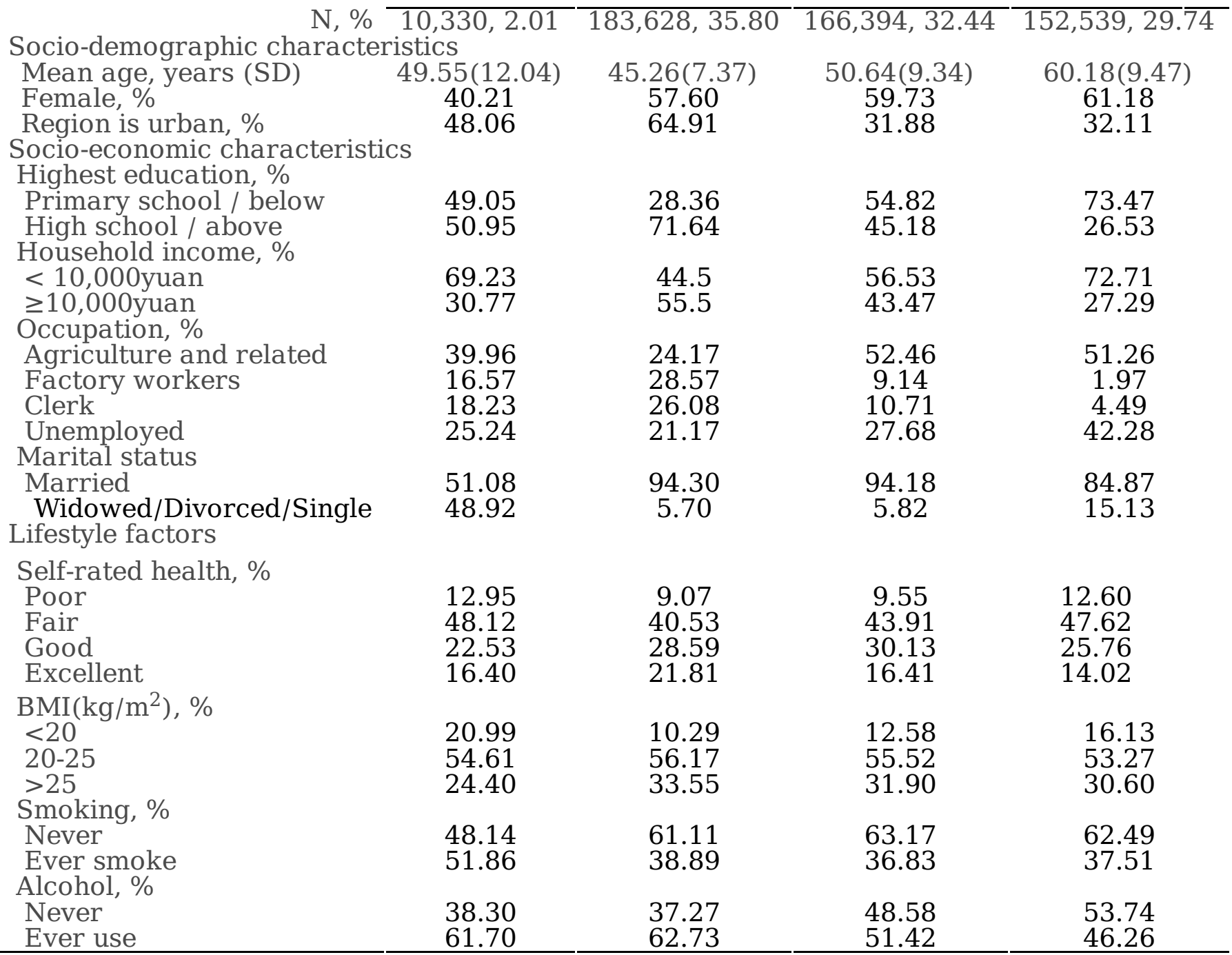

Table 2 The association between number of children and major depression/ insomnia among women and men. 


\begin{tabular}{|c|c|c|c|c|c|c|c|c|}
\hline & \multicolumn{2}{|r|}{ No Child } & \multicolumn{2}{|c|}{ Children $=1$} & \multicolumn{2}{|c|}{ Children $=2$} & \multicolumn{2}{|c|}{ Children $\geq 3$} \\
\hline & $\mathrm{N}, \%$ & OR & $\mathrm{N}, \%$ & OR & $\mathrm{N}, \%$ & OR & $\mathrm{N}, \%$ & OR \\
\hline $\begin{array}{l}\text { Total } \\
\text { Population } \\
\text { Depression }\end{array}$ & & & & & & & & \\
\hline $\begin{array}{l}\text { Crude } \\
\text { Model }\end{array}$ & 122 & $1.97(1.63,2.38)$ & 1,108 & 1 & 1,083 & $1.08(0.99,1.17)$ & 1,027 & $1.12(1.03,1.22)$ \\
\hline $\begin{array}{c}\text { Adjusted } \\
\text { Model }^{\mathrm{a}}\end{array}$ & 1.18 & $1.27(1.00,1.62)$ & 0.60 & 1 & 0.65 & $1.06(0.97,1.16)$ & 0.67 & $0.99(0.88,1.10)$ \\
\hline $\begin{array}{l}\text { Insomnia } \\
\text { Crude }\end{array}$ & 1,875 & $1.38(1.31,1.45)$ & 25,423 & 1 & 26,976 & $1.20(1.18,1.23)$ & 31,610 & $1.63(1.60,1.66)$ \\
\hline $\begin{array}{l}\text { Model } \\
\text { Adjusted } \\
\text { Model }^{\mathrm{a}}\end{array}$ & 18.15 & $1.00(0.93,1.07)$ & 13.84 & 1 & 16.21 & $0.95(0.93,0.97)$ & 20.72 & $0.91(0.89,0.94)$ \\
\hline Female & & & & & & & & \\
\hline $\begin{array}{l}\text { Depression } \\
\text { Crude } \\
\text { Model }\end{array}$ & 59 & $1.90(1.45,2.47)$ & 798 & 1 & 757 & $1.01(0.91,1.12)$ & 757 & $1.01(0.91,1.12)$ \\
\hline $\begin{array}{l}\text { Adjusted } \\
\text { Model }^{\mathrm{b}}\end{array}$ & 1.42 & $1.38(1.03,1.87)$ & 0.75 & 1 & 0.76 & $0.97(0.87,1.08)$ & 0.81 & $0.88(0.77,1.00)$ \\
\hline $\begin{array}{l}\text { Insomnia } \\
\text { Crude } \\
\text { Model }\end{array}$ & 795 & $1.31(1.21,1.42)$ & 16,214 & 1 & 17,890 & $1.21(1.19,1.24)$ & 22,191 & $1.72(1.69,1.76)$ \\
\hline Adjusted & 19.14 & $0.93(0.85,1.02)$ & 15.33 & 1 & 18.00 & $0.94(0.91,0.96)$ & 23.78 & $0.88(0.85,0.90)$ \\
\hline $\begin{array}{l}\text { Male } \\
\text { Total Sampl }\end{array}$ & & & & & & & & \\
\hline $\begin{array}{l}\text { Crude } \\
\text { Model }\end{array}$ & 63 & $2.58(1.96,3.38)$ & 310 & 1 & 326 & $1.22(1.05,1.43)$ & 270 & $1.15(0.97,1.35)$ \\
\hline $\begin{array}{l}\text { Adjusted } \\
\text { Model }^{\mathrm{b}}\end{array}$ & 1.02 & $1.09(0.72,1.66)$ & 0.40 & 1 & 0.49 & $1.30(1.09,1.54)$ & 0.46 & $1.28(1.04,1.58)$ \\
\hline $\begin{array}{l}\text { Total } \\
\text { Sample }\end{array}$ & & & & & & & & \\
\hline $\begin{array}{l}\text { Crude } \\
\text { Model }\end{array}$ & 1,080 & $1.58(1.48,1.69)$ & 9,209 & 1 & 9,086 & $1.17(1.13,1.21)$ & 9,419 & $1.41(1.37,1.45)$ \\
\hline $\begin{array}{c}\text { Adjusted } \\
\text { Model }^{\mathrm{b}}\end{array}$ & 17.49 & $1.05(0.95,1.17)$ & 11.83 & 1 & 13.56 & $0.98(0.95,1.01)$ & 15.91 & $0.96(0.92,1.00)$ \\
\hline
\end{tabular}

a Analyses were adjusted for sex, study region, marital status, age at study date, level of attained education, household income, smoking status, alcohol use, self-rated health, occupation, body mass index.

${ }^{\mathrm{b}}$ Analyses were adjusted for study region, marital status, age at study date, level of attained education, household income, smoking status, alcohol use, self-rated health, occupation, body mass index.

\section{Figures}




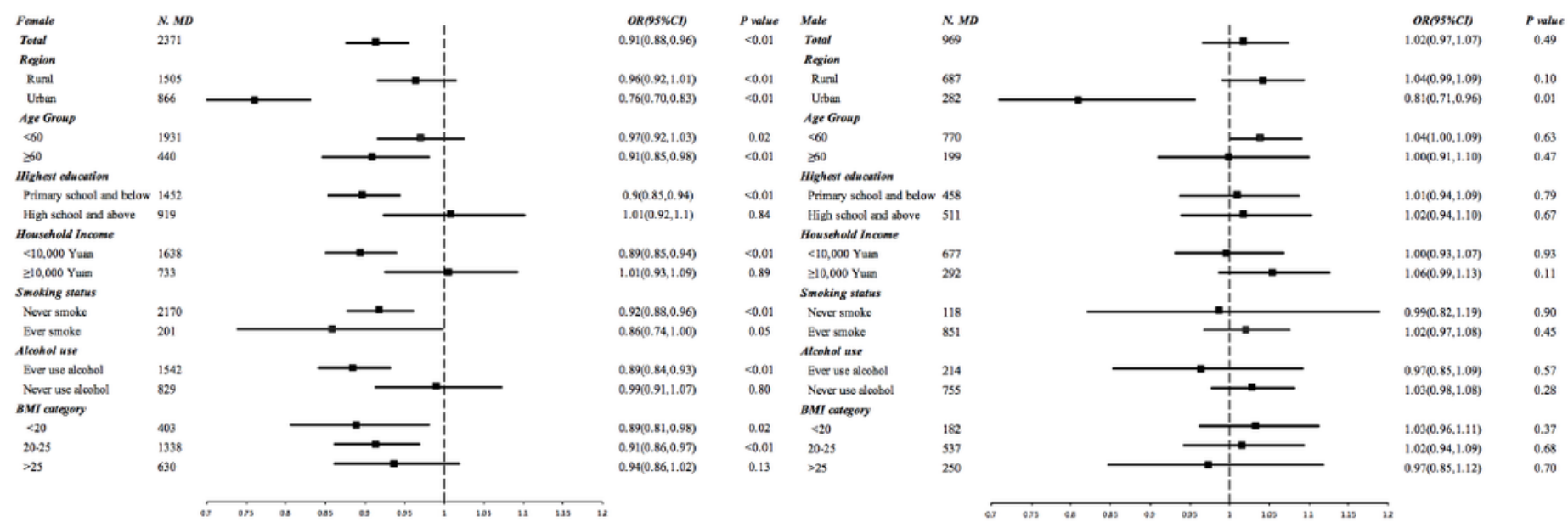

\section{Figure 1}

Adjusted odds ratios $(95 \% \mathrm{Cl}) *$ for major depression per additional child by baseline characteristics in women and men* * Analyses were adjusted for study region, marital status, age at study date, level of attained education, household income, smoking status, alcohol use, self-rated health, occupation, body mass index, where appropriate.

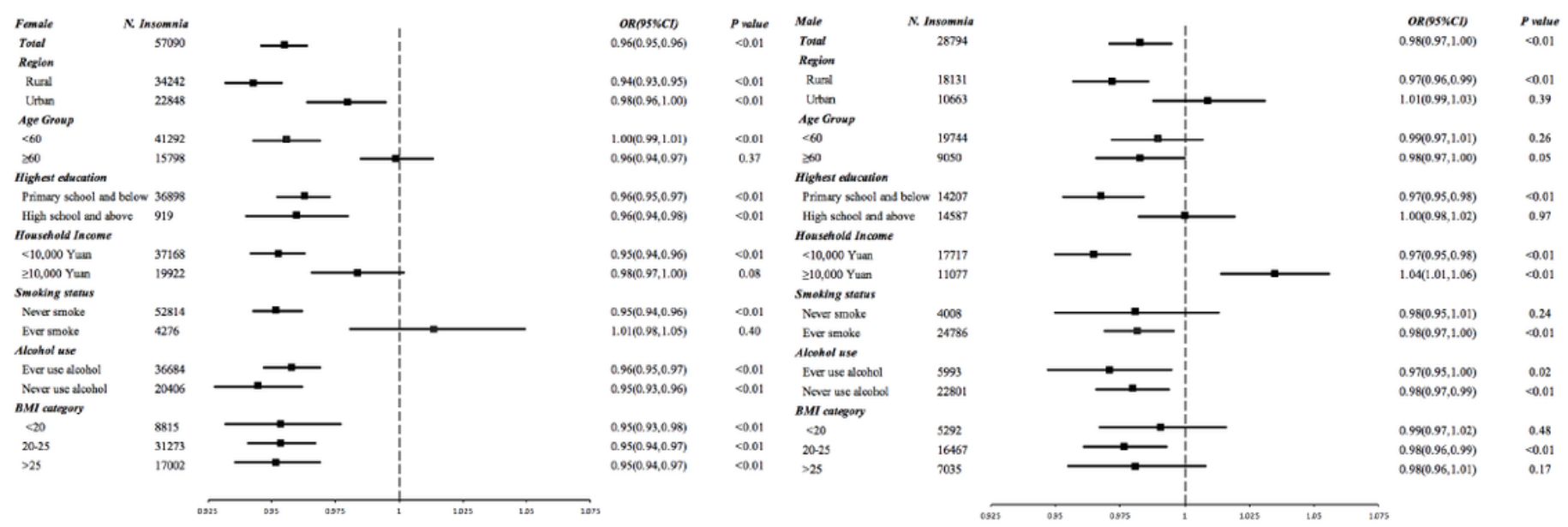

\section{Figure 2}

Adjusted odds ratios $(95 \% \mathrm{Cl})$ * for insomnia per additional child by baseline characteristics in women and men * Analyses were adjusted for study region, marital status, age at study date, level of attained education, household income, smoking status, alcohol use, self-rated health, occupation, body mass index, where appropriate. 